\title{
High-fidelity Simulations Offer a Paradigm to Develop Personal and Interprofessional Competencies of Health Students: A Review Article
}

Nava Livne

Rosalind Franklin University of Medicine and Science, nava.livne@gmail.com

Follow this and additional works at: https://nsuworks.nova.edu/ijahsp

Part of the Interprofessional Education Commons

\section{Recommended Citation}

Livne N. High-fidelity Simulations Offer a Paradigm to Develop Personal and Interprofessional Competencies of Health Students: A Review Article. The Internet Journal of Allied Health Sciences and Practice. 2019 Jan 01;17(2), Article 8.

This Review Article is brought to you for free and open access by the College of Health Care Sciences at NSUWorks. It has been accepted for inclusion in Internet Journal of Allied Health Sciences and Practice by an authorized editor of NSUWorks. For more information, please contact nsuworks@nova.edu. 


\title{
High-fidelity Simulations Offer a Paradigm to Develop Personal and Interprofessional Competencies of Health Students: A Review Article
}

\begin{abstract}
Purpose: Simulation instruction is an effective method to help health professional students develop personal and interprofessional competencies. The purpose of this review was to summarize the literature on high-fidelity mannequin simulation using methods that develop various personal and interprofessional competencies of health students in profession-specific and interprofessional health settings.

Method: This review was conducted using 10 databases, and articles published in English from January 2008 through January 2018 were reviewed. Keywords and terms from the Medical Subject Headings [MeSH] thesaurus were used to create keyword combinations. Of 95 articles that resulted from this search, 44 research studies were chosen for the review.

Results: High-fidelity mannequin simulations improved students' personal and professional competencies in profession-specific environments by $13 \%-63 \%$ depending on the profession. Students acquired knowledge, learned to think critically, and developed self-confidence in implementing clinical skills in practice across different health professions. High-fidelity mannequin simulations also enhanced students' team-based competencies in interprofessional environments by $7 \%$ to $25 \%$. They developed mutual respect, recognized roles and responsibilities, learned to work as a team, and communicated interprofessionally. High-fidelity simulations boosted students' gain in competencies across undergraduate and graduate programs. In three studies, high-fidelity mannequin simulations did not show superiority over standardized patients, paper/pencil scenarios, and low-fidelity simulations.

Conclusions: High-fidelity mannequin simulations offer a paradigm for achieving different competencies across undergraduate and graduate programs and can complement conventional (i.e., lecture-based) instruction. Whereas conventional instruction allows for immediate knowledge gain, high-fidelity mannequin simulations enhance long-term knowledge retention and development of interprofessional competencies. The paradigm is suitable for developing interprofessional team-based skills. Limitations included self-reported data, instruments that lack construct validity, and reduced strength of evidence.
\end{abstract}

\section{Author Bio(s)}

The author is a Ph.D. student in Interprofessional Health Studies at Rosalind Franklin University of Medicine and Science in North Chicago, IL. She earned a Ph.D. in educational psychology at Tel Aviv University in Israel and an MS in nutrition education at Rosalind Franklin University of Medicine and Science.

\section{Acknowledgements}

The author wants to thank Dr. Baker-Rush and DR. Hanson at Rosalind Franklin University of Medicine and Science (North Chicago, IL) for their guidance and support toward this manuscript. 


\title{
1IVAHSP \\ The Internet Joumnal of Allied Health Sciences and Practice \\ Dedicated to allied health professional practice and education
}

Vol. 17 No. 2 ISSN 1540-580X

\section{High-Fidelity Simulations Offer a Paradigm to Develop Personal and Interprofessional Competencies of Health Students: A Review Article}

\author{
Nava Livne, Ph.D., MS \\ Rosalind Franklin University of Medicine and Science \\ United States
}

\begin{abstract}
Purpose: Simulation instruction is an effective method to help health professional students develop personal and interprofessional competencies. The purpose of this review was to summarize the literature on high-fidelity mannequin simulation using methods that develop various personal and interprofessional competencies of health students in profession-specific and interprofessional health settings. Method: This review was conducted using 10 databases, and articles published in English from January 2008 through January 2018 were reviewed. Keywords and terms from the Medical Subject Headings [MeSH] thesaurus were used to create keyword combinations. Of the 95 articles that resulted from this search, 44 research studies were chosen for the review. Results: High-fidelity mannequin simulations improved students' personal and professional competencies in profession-specific environments by $13 \%-63 \%$ depending on the profession. Students acquired knowledge, learned to think critically, and developed self-confidence in implementing clinical skills in practice across different health professions. High-fidelity mannequin simulations also enhanced students' team-based competencies in interprofessional environments by $7 \%$ to $25 \%$. They developed mutual respect, recognized roles and responsibilities, learned to work as a team, and communicated interprofessionally. High-fidelity simulations boosted students' gain in competencies across undergraduate and graduate programs. In three studies, high-fidelity mannequin simulations did not show superiority over standardized patients, paper/pencil scenarios, and low-fidelity simulations. Conclusions: High-fidelity mannequin simulations offer a paradigm for achieving different competencies across undergraduate and graduate programs and can complement conventional (ie, lecture-based) instruction. Whereas conventional instruction allows for immediate knowledge gain, high-fidelity mannequin simulations enhance long-term knowledge retention and development of interprofessional competencies. The paradigm is suitable for developing interprofessional team-based skills. Limitations included self-reported data, instruments that lack construct validity, and reduced strength of evidence.
\end{abstract}

Keywords: High-fidelity, simulation, student personal skills, interpersonal competencies, profession-specific, interprofessional, environments

(c) The Internet Journal of Allied Health Sciences and Practice, 2019 


\section{INTRODUCTION}

Simulation instruction has been recommended as an effective method to help health professional students learn to collaborate interprofessionally. ${ }^{1}$ Simulation mimics clinical patient care situations as close as possible and allows students to gain "hands-on" experience while applying new knowledge and skills to clinical practice in a realistic and safe environment. ${ }^{2}$ There are several modalities of medical simulation, ranging from standardized patients to low- and high-fidelity simulations. ${ }^{3}$ Standardized patients are trained people who "act" in the role of patients. Low-fidelity and high-fidelity simulations provide life-like models of actual patients. They involve the most advanced information technologies.., 5

With respect to simulation, fidelity refers to a continuum on which the degree of learners' perceived realism or authenticity ranges from completely artificial to an accurate representation of real-life cues and stimuli learning episodes. ${ }^{6,7}$ High- and low-fidelity simulations vary in their degree of physical fidelity. High physical fidelity encompasses more features that can be manipulated by the student, giving more realistic context for measuring clinical and nontechnical skills and competencies in various invasive procedures and decision-making. -9 $^{-9}$ Low physical fidelity simulation, in turn, is static and does not allow students to interact with the environment.,5,10,11 Low-fidelity simulations are designed to develop manual or technical skills that can be learned only through repetitive practice. ${ }^{1}$

High-fidelity mannequin simulation (HFS) uses a computerized mannequin, and it more closely mimics the real-life clinical environment. It can replicate physiological responses such as heart rate or lung sounds, and it provides feedback in response to students' actions, e.g., changes in respiratory rate, heart rate, heart and lung sounds, sweating, bleeding, and response to medication therapy.4,12 High-fidelity patient mannequins are often used for team-oriented trainings. They allow students to work together and to learn from their mistakes in a safe environment without causing adverse consequences to real patients. ${ }^{13,14}$

The high-fidelity mannequin simulation modality is adaptable to a variety of medical situations and can be tailored to different learning objectives. ${ }^{15}$ Due to its adaptability, this modality offers an individualized learning experience in which clinical competence is built through progression from knowledge through integrated knowledge, competence, and performance. ${ }^{16}$ Progression through these stages occurs if curriculum integration, skill acquisition, and professional context are incorporated into HFS in professionspecific health programs ${ }^{17}$ Emphasis is placed on knowledge acquisition and the achievement of clinical skills, self-efficacy, and confidence., $, 10,11$ Profession-specific knowledge acquisition and experience with HFS can also be transferred to clinical and teambased competencies of students as a transition to an interprofessional milieu. ${ }^{18,19}$ Recently, high-fidelity mannequin simulation has also been used in clinical situations, as it provides a setting to make mistakes without consequences to real patients, along with exposure to repeated procedures and rare and common experiences while practicing teamwork. ${ }^{13,20}$

Compared to other simulations, high-fidelity mannequin simulation, due to its realistic nature, offers the best opportunity for students to apply knowledge to real life situations and gain collaborative competency. ${ }^{21}$ Collaborative competencies are a set of desired principles that can be acquired in interprofessional (IP) learning; i.e., two or more students who learn about, from, and with one another in order to empower them to collaborate and improve patient outcomes. ${ }^{22}$ Students are expected to become proficient in the four Interprofessional Education Collaborative (IPEC)] core competencies. Competency 1 refers to developing values/ethics for IP practice and represents the "work of individuals from other professions to maintain a climate of mutual respect and shared values."22(p19) Competency 2 indicates the appreciation of one another's roles and responsibilities and signifies the "use [of] knowledge of one's own role and those of others to appropriately assess and address healthcare needs of patients."20(p21) This competency focuses on recognizing one's own limitations in skills, knowledge, and abilities while forging interdependent relationships with other health professionals. Competency 2 is built on Competency 1 in that no appreciation of one another's roles can be obtained without shared values and mutual respect. ${ }^{23}$ Competency 3 refers to the ability to "communicate with patients ... and other health professionals" within a team setting. ${ }^{22(223)}$ Competency 3 is built on Competencies 1 and 2, as no IP communication can occur without recognizing one's uniqueness and professional role while expressing thoughts with clarity and respect. Last, Competency 4 stands for the ability "to apply relationship-building values and principles of team dynamics to perform effectively in different roles to plan and deliver patient-centered care."22(p25) Teamwork centers on establishing consensus on ethical principles and integrating the knowledge and experience of others into collaborative teams, as team members demonstrate accountability to one another. The purpose of this review was to summarize the literature on high-fidelity mannequin simulation using methods that develop various personal and interprofessional competencies of health students in profession-specific and IP health settings.

\section{METHODS}

\section{Search Strategy}

A search strategy was implemented to find the most pertinent, evidence-based, peer-reviewed articles concerning the use of HFS to help health professional students achieve professional and IP competencies. Ten scientific literature databases were searched: PubMed and its primary MEDLINE sub-database, CINAHL Complete, PsycINFO, Academic Search Complete, Directory of Open

(C) The Internet Journal of Allied Health Sciences and Practice, 2019 
Access Journals, Professional Development Collection, Complementary Index, Supplemental Index, Nursing/Academic Edition, and Google Scholar. Articles published in English from January 2008 through January 2018 were searched, unless the articles had been cited as secondary sources in earlier years or had been either peer-reviewed studies or systematic reviews. Keywords or terms were chosen from the Medical Subject Headings [MeSH] thesaurus. Boolean operators, AND/OR, were used to create combinations of keywords that narrowed or broadened the search.

Six keyword combinations were utilized: 1) (simulations OR simulated-based learning) AND (interprofessional education); 2) (simulation) AND (health professional students that specialize in delivery of patient care and were the target audience for this review); 3) (simulation) AND (critical event) AND (medical OR nursing OR physical therapy OR pharmacy OR occupational OR respiratory therapy); 4) (High-fidelity OR low-fidelity simulation OR simulated/virtual patient) AND (interprofessional communication OR collaboration OR teamwork) AND (health professional students); 5) (high-fidelity simulation) AND (knowledge OR confidence OR skills) AND (interprofessional health students); and 6) (high-fidelity simulation) AND (profession-specific OR interprofessional competencies) AND (health students).

Inclusion of studies met at least four of the following criteria: 1) articles published from January 2008 through April 2018; 2) articles that highlight topics for future research on HFS or peer-reviewed articles with experimental designs ${ }^{24} ; 3$ ) experimental designs, including randomized controlled pretest-posttest experiments, observational studies, or self-report surveys; 4) students in health professions who studied in IP learning environments that involved high-fidelity simulations; 5) samples including at least 25 participants that are minimally acceptable for parametric statistical analysis even when the standard deviation for the population is unknown or using nonparametric analysis for nominal or ordinal data correctly25;6) simulation activities included debriefing sessions, as they are considered an important component in simulation 20,$26 ; 7)$ a $70 \%$ response rate, which is the minimally acceptable response rate for health professions 27,$28 ; 8$ ) outcome measures based on reliable (Cronbach $\geq 0.7$ ) instruments that had at least content validity due to the scarcity of well-documented measurement across simulation scenarios 29 ; 9) data analysis included parametric or nonparametric tests, and the level of significance was set up at $p<.0525 ; 10$ ) outcome measures related to profession-specific knowledge, confidence, or self-efficacy; and 11) intra- or interprofessional communication, collaboration, or teamwork. Study design, data analysis, and the significance level were used to determine the quality or the strength of evidence of research.

Exclusion criteria were as follows: 1) articles published in 2007 or earlier, unless they were categorized as classic or landmark works that presented venues to new research ${ }^{11}$; 2) systematic reviews; 3) full-text book chapters and policy papers, because these did not discuss evidenced-based findings; 4) low-fidelity and/or standardized patient simulation articles; 5) students from nonhealth professions; 6) outcome measures that relied on instruments with low or unknown reliability and validity; 7) small samples $(n<25)$ with a response rate smaller than $70 \%$ and case studies, unless they used randomized controlled designs, special use of HFS, or were unique to a specific profession ${ }^{27}$; and 8) clinicians or practitioners.

Collectively, 95 articles were initially identified across the 10 databases, including articles found in citations. Of them, studies were chosen only if they met the initial inclusion criteria, resulting in 18 articles in PubMed, 30 articles in CINAHL, 5 articles in PsycINFO, 4 in Academic Search Complete, 6 in Directory of Open Access, 2 in Professional Development Collection, 2 in Complementary Index, 1 in Supplemental Index, 1 in Nursing/Academic Edition, and 2 articles in Google Scholar.

Excluding duplicates, 66 articles that were related to the effect of high-fidelity simulations on students' competencies within and across health professions and met the inclusion criteria were used for this review. Articles that reported research findings were chosen where their evidence strength was at least fair. For those studies, sufficient evidence was available to determine the effectiveness of HFS on student learning, but the confidence in their strength was constrained by limited generalizability due to systematic biases in the study design, nonparametric analysis that reduced the study level of significance to a p value greater .05 , and small sample sizes, based on the GRADE scale. ${ }^{30}$ That included studies where the design ranged from pretest-posttest through mixed methods and quasi-experimental designs to randomized controlled trials; and outcome measures were either self-reports or objective assessments. For this review, 44 research articles, which met the evidence strength criteria cited above or were based on a response rate of $\geq 70 \%$, were chosen for the current review. Of them, 22 articles discussed the effect of HFS methods on students' personal competencies, while 22 articles expounded the impact of HFS techniques on stimulating students' IP competencies. Figure 1 illustrates the review process and study selection.

(c) The Internet Journal of Allied Health Sciences and Practice, 2019 


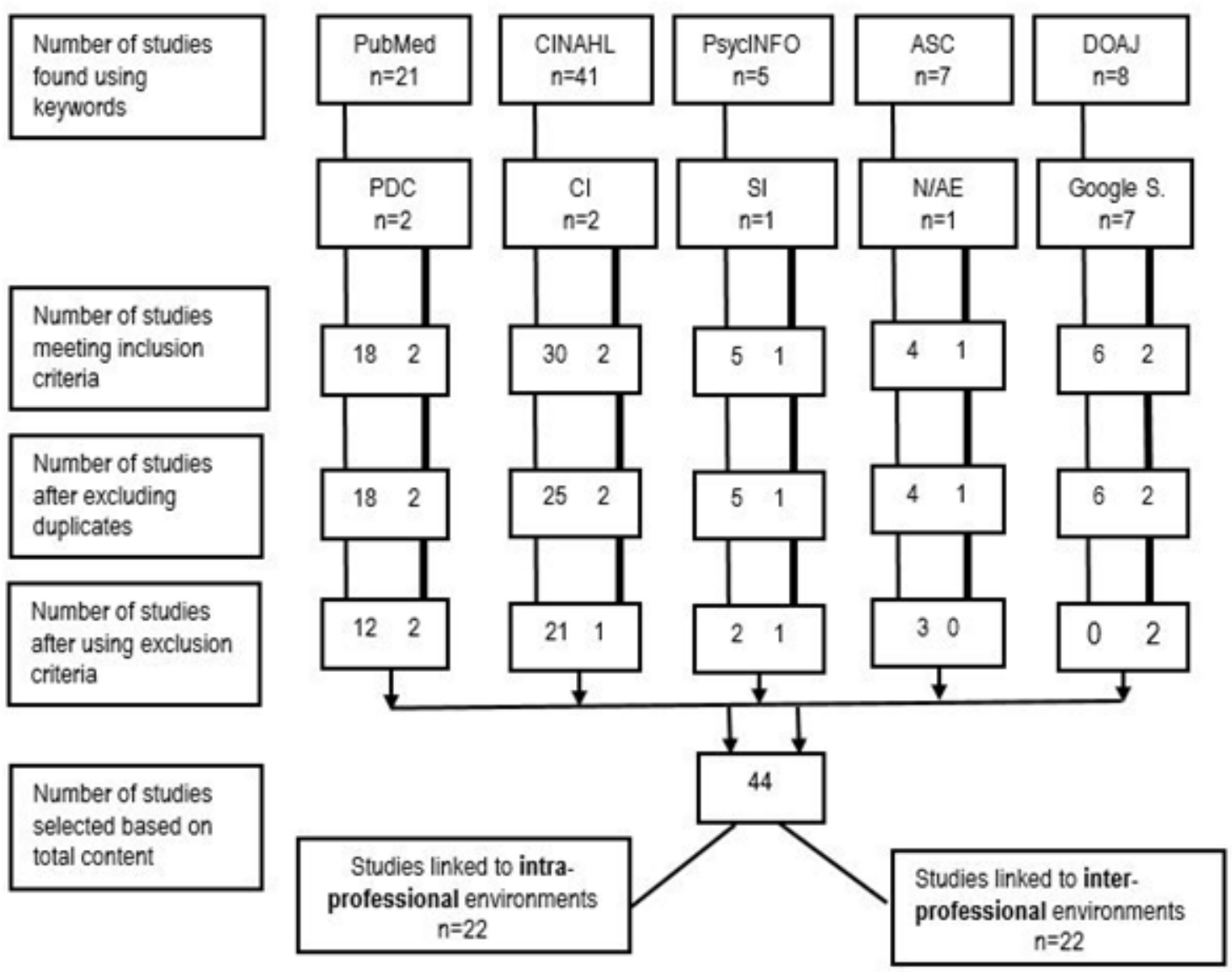

\section{Abbreviations: $A S C=$ Academic Search Complete; DOAJ = Directory of Open Access Journals; PDC = Protessional Development Collection; $\mathrm{Cl}=$ Complementary Index; $\mathrm{SI}=$ Supplemental Index; $\mathrm{N} / \mathrm{AE}=$ Nursing/Academic Edition; Google S = Google Scholar}

Figure 1. A flow of the review process and selection of studies related to the effect of high-fidelity simulations in intraprofessional and interprofessional learning environments.

\section{Competencies in Profession-Specific Milieus}

High-fidelity simulations promote students' competencies in diverse clinical care scenarios in a simulated, safe, profession-specific environment. ${ }^{31}$ Although evidence suggests that HFS enhances students' knowledge, clinical skills, and self-confidence, the number of studies investigating the effect of HFS on students' competencies in the U.S. has been limited.32 Moreover, knowledge gained through HFS was not always measured by instruments with sufficient sensitivity and specificity to explain insignificant simulation effects, when compared to other learning methods. ${ }^{33}$ Because of these limitations, this review included studies on the impact of HFS on students' competencies in the U.S. and around the world. Seven countries-Australia, Canada, India, Korea, Singapore, Sweden, and the U.K.-either made similar uses of HFS in various health professions or indicated similar competency improvement as that observed in the U.S., and studies relevant to those countries met the inclusion criteria. Although health professional programs in other countries may differ in their purposes, duration, activities, measuring instruments, and professional specifications for using HFS, lessons from their experiences may be of value in developing educational experiences in other geographic areas.

The term "competency" is defined as the characteristics that encompass performance, including knowledge, skills, and attitudes required for delivering high value care to improve patient outcomes. ${ }^{22,34-36}$ Knowledge is associated with learning objectives and learning activities at the pre-licensure level, which allows flexibility for health educators to develop profession-specific characteristics of performance to prepare students for practice. ${ }^{34}$ Skills are defined as the "tasks to be performed, the conditions under which those tasks are performed, e.g., high-fidelity simulations and the standards to be achieved in performing the task." 35 (p2) 
Attitudes are defined in terms of the ethical considerations and decision-making skills that determine clinical reasoning and judgement related to clinical practice. ${ }^{22}$ Simulation-based learning strategies have a favorable impact on self-efficacy and motivation for learning that affects acquisition of personal competencies, e.g., knowledge acquisition or comfort level and technical or clinical skills when used in profession-specific milieus. ${ }^{9,10,37}$ Accordingly, studies are presented for each profession separately.

\section{The use of high-fidelity simulations in nursing}

High-fidelity simulations have been most often used to train undergraduate nursing students to acquire nursing competencies. Nursing students $(n=314)$ at the University of Montreal, Canada, participated in two days of HFS activities in a qualitative, pilot study as part of their clinical placement. ${ }^{38}$ Students reported that HFS helped them develop clinical reasoning, link the classroom content to real practice, and to practice clinical skills along with leadership and collaboration. They also gained confidence and learning from their mistakes in a safe environment, as indicated by their responses to an open-ended questionnaire developed by faculty, using content analysis. At Chonbuk National University, Korea, 70 undergraduate maternity nursing students learned to manage normal and high-risk deliveries of pregnant women through three HFS sessions in a quasi-experimental pretest-posttest design. ${ }^{39}$ Students' communication skills and clinical competencies were assessed by instructors using two objective instruments that exhibited excellent reliability and content validity. Students improved their clinical competence, patient education, basic nursing performance, and direct nursing intervention by $18 \%$, which was higher when compared to $4 \%$ of the corresponding measures in the control group at $p<.01$ level of significance. Communication skills were improved by $16 \%$ for students who received HFS, as evidenced by an increase of 3.69 to 4.16 , in their pretest-posttest mean scores on a 5-point scale, compared to $3 \%$ for the control using $t$-test analysis for independent sample at $p<.05$ significance level. Lee et al reported on 49 undergraduate senior nursing students at Pusan National University, Korea, who participated in 20-minute HFS scenarios on managing postoperative care using a quasi-experimental non-equivalent control group pretest-posttest design. ${ }^{40}$ Students' responses were measured by three selfreported reliable and valid scales, the Kolb Learning Style Inventory, Nursing Core Competencies, and the Problem-solving Skills scale. Post simulation, students improved in nursing competencies by $13 \%$, perceived critical reasoning by $39 \%$, communication with patients by $24 \%$, and self-confidence by $5 \%$, which were higher from the corresponding measures of a control group using analysis of covariance (ANCOVA) test at a $p<.05$ significance level. Students' scores for problem-solving and academic selfefficacy were higher in the intervention group than those in the control group, but the differences were not statistically significant.

Ignacio et al investigated 57 undergraduate third-year nursing students at the National University of Singapore, Singapore, who participated in three HFS deteriorating-patient scenarios in a randomized controlled design as part of a clinical reasoning course. ${ }^{41}$ Students worked in teams to manage the status of a simulated patient with high blood glucose who was moderately confused, a patient with giddiness and low blood pressure, and a patient with chest pain and tachycardia. Student performance was assessed by two faculty members using the Rescuing A Patient in Deteriorating Situations (RAPIDS) instrument that achieved good construct validity and inter-rater reliability. Stress was measured using salivary a-amylase levels at pretest and posttest. Post intervention, students improved their observed clinical competencies and their management of self-stress by $20 \%$ as measured by their decreased saliva alpha-amylase levels using a paired $t$-test at $p<.05$ significance level. Students also demonstrated increased confidence in managing a simulated patient-deterioration in an acute care setting as assessed by trained raters. However, students perceived a standardized patient as more valuable in preparing students for actual practice than HFS as indicated in focus group interviews.

Tosterud et al found similar results in 86 undergraduate third-year nursing students at Karlstad University, Sweden, that participated in three HFS scenarios related to a patient experiencing fluctuations in the severity of chronic obstructive pulmonary disease (COPD). ${ }^{3}$ Post intervention, students self-rated their responses on three scales: the Student Satisfaction and Self-Confidence in Learning Scale (SSS), the Educational Practices Questionnaire (EPSS), and the Simulation Design 20-item Scale (SDS). All the instruments were valid and exhibited high reliability. The results indicated that students gained perceived self-confidence in performing the appropriate actions to stabilize a patient in a clinically acute setting. High-fidelity simulation provided cognitive, psychomotor, and affective challenges, while students who participated in paper/pencil case scenarios focused on theoretical learning. Nevertheless, students in the paper/pencil group were more satisfied than were those in the HFS group, as measured by the Mann-Whitney U-test at statistical significance of $p<0.01$.

At McMaster University, Canada, 48 undergraduate nursing students participated in two HFS sessions. ${ }^{42}$ Outcome measures included written responses to 10 open-ended questions on a satisfaction survey that was transcribed and grouped into key themes by three investigators. Based on a consensus regarding the key themes, reflecting inter-rater reliability, the data were analyzed and revealed that students improved their perceived personal and professional skills by learning to manage the health condition of two adult patients with cardiac irregular functions and of a child who had a pediatric respiratory condition. Results indicated that students recognized their unique strengths and their ability to contribute to nursing care, while supporting one another and respecting the distinct roles within their intra-team. The high-fidelity simulation activities facilitated students' clinical reasoning and

(c) The Internet Journal of Allied Health Sciences and Practice, 2019 
self-confidence. The findings suggest that "intraprofessional team training with high-fidelity simulation provides unique learning opportunities for undergraduate nursing students." $429($ (p631)

\section{The use of high-fidelity simulations in medicine}

High-fidelity simulations have also been used to train medical students. Cortegiani et al examined the effect of three HFS sessions on 94 undergraduate second-year medical students at the University of Palermo, Italy, using a randomized controlled pretestposttest design. ${ }^{33}$ The simulation scenarios focused on implementing Advanced Life Support (ALS) guidelines intended to help students rotate roles in stabilizing the status of a simulated patient in cardiac arrest with an endotracheal tube in place. Outcome measures included the overall number of correct answers to questions on an objective section that measured knowledge level and a subjective evaluation of personal perceived knowledge acquisition using a questionnaire that exhibited content validity. The intervention group included 46 students who received HFS sessions, while 48 randomized students were in the control group. Post simulations, students in the intervention group had increased their knowledge by $13 \%$ when compared to those in the control, as indicated by a difference of 74.1 and 65.5 in mean scores of correct answers in their posttest mean scores, respectively, using the Welch $t$-test for unequal variances at $p<0.0001$ significance level. The simulations also enhanced students' perceived communication skills by $21 \%$ higher than those of the control, as indicated by a difference of 22.4 .1 and 18.5 in posttest mean scores of correct answers, respectively, at $p<0.006$.

Alluri et al found similar results among 20 undergraduate second-year medical students at the School of Medicine, University of California Los Angeles, CA, who participated in two HFS sessions using a randomized controlled trial. 43 The simulation scenarios involved a patient with an inferior wall myocardial infarction and a patient with suspected hyperkalemia secondary to renal failure. Students' knowledge of the pathophysiology of each patient's condition was measured by the average percentage of correct responses to a knowledge questionnaire that exhibited content validity. Results showed that students solidified their knowledge, as shown by an increase of $14 \%$ from a mean score of 40.00 to 55.00 of their pretest-posttest correct answers using a two-tailed Student's $t$-test at $p<0.05$ significance level. They also strengthened their long-term knowledge retention, as indicated by a $50 \%$ increase in their mean scores five weeks post intervention at $p<0.05$.

At the University of Pramukhswami Medical College, India, 103 undergraduate neonatal medical students participated in a threeday HFS workshop on neonatal resuscitation as part of a pretest-posttest randomized controlled trial. ${ }^{5}$ Post intervention, participants responded to a Megacode questionnaire-a validated instrument developed by the American Academy of Pediatrics, testing the psychomotor and cognitive skills of resuscitating a newborn. Students had improved their knowledge and cognitive/psychomotor skills by $58 \%$ and $39 \%$, as shown by their pretest-posttest and delayed mean scores three months later, respectively, using paired a $t$-test at $p<0.001$ level of significance. Ninety-five percent $(n=88)$ of the students reported perceived confidence to assist a senior person in such a situation. The results suggest that knowledge and skill retention provided students with an opportunity of self-learning and may strengthen them. Nguyen et al confirmed this finding among 120 undergraduate firstyear medical students at the University of Central Florida. ${ }^{44}$ Students participated in four one-hour HFS scenarios on patients who experienced heat exhaustion, congestive heart failure, COPD, and diabetic ketoacidosis. Post simulations, the Basic knowledge quiz-an objective measurement that achieved face and content validity-was administered to the students. Two faculty members rated five observable behaviors on a reliable and valid Critical Thinking Skills Rating Instrument (CTSRI). Results showed correlations between students' basic knowledge and critical thinking, as evidenced in students' pretest-posttest mean scores using Spearman correlations $(r s)$ at $p<.05$ significance level.

Teske et al found a similar effect in a one-hour HFS session on 24 graduate pediatric and internal pediatric medical residents at the University of Alabama at Birmingham in a qualitative study..$^{45}$ Participants learned to manage malnutrition and nutrient deficiencies of an infant patient and self-reported their perceived knowledge of addressing nutrition-related disease-specific states of infants using a rating scale that achieved content validity. At the end of the course, students reported perceived improvement in knowledge, i.e., in the ability to identify signs and symptoms of nutritional trace element deficiencies. Ninety-six percent $(n=23)$ of them also strengthened their perceived clinical skills using frequency of responses. Together, these findings show that HFS activities are beneficial for achieving medial personal competencies, e.g., nutrition knowledge acquisition and the development of critical thinking and problem-solving for medical students, filling educational gaps in clinically relevant aspects of nutrition.

\section{The use of high-fidelity simulations in pharmacy}

Pharmacy programs also use HFS to prepare students for clinical practice. At the Philadelphia Pharmacy College, PA, 194 graduate pharmacy students participated in a 30-minute HFS session involving cardiac events as part of a parallel-group observational study conducted during a critical care therapeutics course. ${ }^{10}$ Using the Advanced Cardiac Life Support (ACLS) validated scale, students' skills were measured by an objective evaluation based on American Heart Association guidelines by two trained pharmacotherapy specialist raters along with the primary simulation outcome (mannequin survival or death). At the end of

(C) The Internet Journal of Allied Health Sciences and Practice, 2019 
the session, students improved their knowledge and advanced cardiac life support skills, as assessed by the percentage of correct answers on administration of correct antiarrhythmic drug and dose $(69 \%$ correct answers before simulation training vs. $100 \%$ correct answers after training) and survival rate (33\% correct answers before simulation training vs. $70 \%$ correct answers after simulation). Students also demonstrated stronger knowledge retention and self-confidence in applying their improved skills to new situations three months later using the non-parametric Mann-Whitney $U$ test for independent sample (ACLS and survival rate) at $p<.05$ significance level.

Branch showed a positive effect of HFS on 123 undergraduate second-year pharmacy students at Medway School of Pharmacy, UK. ${ }^{2}$ Students engaged in a 20-minute simulation session, observing a patient with drug-induced dyspepsia with gastrointestinal bleeding in a pretest-posttest cohort design. Students' knowledge of dyspepsia and their ability to recognize dyspepsia-associated symptoms were assessed by their responses to a valid simulation knowledge test. Post simulation, students demonstrated improvement in their observed knowledge of dyspepsia and its associated signs, as measured by an increase of $42 \%$ in their correct answers from a 15.5 mean score at pretest to a 22.0 mean score at posttest using a paired $t$-test, $p<.05$ level of significance. The majority of students $(n=79)$ improved their clinical performance skills, particularly in problem-solving and selfconfidence, and were satisfied with the simulation experience.

Smith et al found similar findings among 105 graduate third-year pharmacy doctoral students at the University of Pittsburgh, PA. ${ }^{46}$ Students practiced disease diagnosis, treatment, therapy, and patient counseling on an HFS patient experiencing various stages of asthma as part of a one-group pretest-posttest design. Using objective pre-simulation and post-simulation knowledge assessments of six open-ended questions that achieved face and content validity, students improved their observed knowledge and critical thinking. There was also a $9 \%$ increase in the number of correct answers on basic knowledge questions and a $20 \%$ increase in problem-solving questions using chi-square tests for nominal data or the Fisher exact test if the data did not meet the criteria for chi-square analysis. Seventy-two percent $(n=76)$ of the students stated that HFS was an effective way to learn, while $59 \%(n=62)$ of them recommended incorporating HFS into the curriculum. The findings suggested that HFS allowed students repetition of the course content, engagement in patient-centered learning, and high levels of thinking while enjoying the simulationbased experience. This finding was confirmed among 78 graduate third-year pharmacy students at North Dakota State University, $\mathrm{ND}$, in a randomized cross-over comparison design. ${ }^{9} \mathrm{~A}$ high-fidelity patient simulator injection arm allowed students to practice and properly administer subcutaneous and intramuscular injection to a peer. Outcome measures were produced by two types of assessments: 1) an objective measurement that assessed students' demonstrated competence to administer an injection; and 2) a subjective self-reported rating survey, which was validated in an earlier study, and measured students' proficiency, confidence, and anxiety before and after practicing injections. Post simulations, $100 \%$ of students administered the injections properly, while $97 \%$ of them inserted the needle quickly using steady pressure. Students also improved their perceived proficiency and confidence in independently administering an injection to a peer and reduced their perceived anxiety after practicing injections. Using an analysis of variance (ANOVA) at $p<.05$ significance level and Mann-Whitney and Median Sign tests at $p<.05$, the findings also showed that there was not a difference in students' anxiety, proficiency, confidence, or ability to administer injections, following high- versus low-fidelity simulations. Together, the results indicate that practicing injection technique with either HFS or low-fidelity simulations improves pharmacy students' personal competencies, including knowledge and confidence in implementing clinical skills in practice.

\section{The use of high-fidelity simulations in other health professions}

In contrast to the frequent use of HFS in nursing, medical, and pharmacy education, fewer studies examined the influence of HFS on students in other health professions. For example, 46 graduate occupational therapy doctoral students at the University of Florida, FL, learned to respond to a critical event using a 15-minute HFS patient in the intensive care unit in a quasi-experimental mixed methods design. ${ }^{47}$ Students mobilized a simulated patient to the edge of the bed and practiced their response to changes in the patient's heart rate, blood pressure, and oxygen saturation. Self-reported rating scales that demonstrate content validity assessed students' perceived knowledge, comfort, and confidence to practice occupational therapy clinical skills. Post simulation, students had increased their perceived knowledge, confidence, and comfort level in managing the patient's physiological changes after participating in an acute care simulation. There was an $80 \%$ increase in their pretest-posttest rating on a five-point Likert scale using a two-tailed Wilcoxon Signed-Ranks test for ordinal data that were higher than pretest ranks.

Silberman et al showed that when 16 graduate second-year Doctor of Physical Therapy (DPT) students in Northeastern University of Boston, MA, participated in six 5-minute HFS sessions, they improved their knowledge of clinical care. ${ }^{48}$ In the first scenario, students practiced patient/family communication related to the patient's condition, progressing in complexity to the final scenario involving a patient on a ventilator in a simulated emergency room. Using the self-reported Acute Care Confidence Survey (ACCS) that possessed content validity, students strengthened their perceived self-efficacy and confidence in managing the patient's condition following the HFS. Self-efficacy within group performance was examined using a Friedman's analysis of variance

(C) The Internet Journal of Allied Health Sciences and Practice, 2019 
(ANOVA) to determine differences on the ACCS. Post-hoc analysis was completed with related samples using the Wilcoxon signed rank test. Qualitative data were analyzed for thematic content. An increase of $20 \%$ in students' perceived knowledge of the ACS and their ability to safely manage the environment pretest-posttest mean scores was reported, and there was a $9 \%$ increase in their posttest-midterm clinical practice scores. Students also reinforced their confidence in the perceived ability to handle multitasking due to improved clinical reasoning, while communicating their knowledge and skills to their clinical instructors. The findings suggest that HFS in physical therapy education may lead to increased self-efficacy for acute practice and could be integrated into the profession curriculum.

At Curtin University, Australia, 60 undergraduate senior pre-registered physiotherapy students completed an 18-day HFS placement, composed of three 6-day HFS periods. ${ }^{18} \mathrm{~A}$ total of 25 simulation scenarios involved patients with a musculoskeletal, neurological, and cardiopulmonary health conditions in a pretest-posttest design. Students' performance was assessed by two measures, both of which demonstrated confirmed validity. The Assessment of Physiology Practice (APP) instrument evaluated students' observed professional and clinical competence by clinical supervisors. A self-reported confidence survey assessed students' perceived confidence in practicing physiotherapy clinical skills. Differences in confidence scores for each 6-day period during the placement and from day one to day six of the placement were analyzed using paired $t$-tests. Confidence scores at the end of each of the 6-day blocks were also analyzed using repeated measures ANOVA at $p<.05$ significance level. Post simulations, students reported improved perceived confidence following each of the three 6 -day simulation sessions by $35.8 \%$ for cardiorespiratory, $35.7 \%$ for neurology, and $36.0 \%$ for musculoskeletal skills in clinical rotations for each of the 6-day blocks. However, "there was no cumulative improvement over the entire (18-day HFS) placement."18(p5) Additionally, students, who completed the simulation-based placement, achieved higher APP scores overall in their subsequent clinical placement compared to students who had no simulation-based learning, as evaluated by clinical supervisors. The findings suggest that HFS in physical therapy education supports students' perceived and observed confidence to practice within a clinical placement block, but further improvement across clinical placement blocks may not be seen. ${ }^{18}$

At Georgia State University, GA, 19 graduate dietetic students in the coordinated program participated in a 15-minute HFS activity on a simulated patient with multiple comorbidities, who had experienced trauma as part of a repeated measure, in a cohort-based design. ${ }^{49}$ Self-reported scales were used to assess students' levels of self-efficacy before and after supervised clinical practice. The Wilcoxon signed-rank test was used to examine the difference in median confidence level before and after the simulation experience and the difference between the confidence level after simulation and during the supervised clinical practice rotation at $p<.05$ significance level. Post simulation, students showed improved self-efficacy in completing a task to manage a simulated clinical situation. Students reinforced their perceived self-confidence during performance in supervised clinical practice, as assessed by a $47 \%$ increase from 1.5 to 2.2 in their median level scores on a 4-point scale, supporting the use of HFS with dietetics students that can supplement supervised practice experiences.

Overall, the findings suggest that HFS may enhance students' personal and profession-specific competencies. Students improved observed and self-reported knowledge acquisition, critical thinking, self-confidence, and self-efficacy across simulation scenarios at different health professions. In some health professions, e.g., nursing and medicine, HFS also facilitated students' mutual respect, role recognition, communication skills, and developed profession-specific solidarity. ${ }^{33,39}$ Table 1 summarizes the effect of HFS on the students' gain of personal and profession-specific competencies matched to the type of program and measurement type in intraprofessional milieus.

(C) The Internet Journal of Allied Health Sciences and Practice, 2019 
Table 1. Students' Gain of Personal Competencies Matched to Type of Measurement through High-Fidelity Simulations

\begin{tabular}{|c|c|c|c|}
\hline Profession-specific Students & Type of Program & Type of Measurement & Personal-professional competencies \\
\hline Nursing & $\begin{array}{l}\text { - Undergraduate } \\
\text { - Undergraduate } \\
\text { - Undergraduate } \\
\text { - Undergraduate } \\
\text { - Undergraduate } \\
\text { - Undergraduate } \\
\text { - Undergraduate } \\
\text { - Undergraduate }\end{array}$ & $\begin{array}{l}\text { - Self-reports } \\
\text { - Self-reports } \\
\text { - Valid assessment } \\
\text { - Self-reports } \\
\text { - Valid assessment } \\
\text { - Self-reports } \\
\text { - Self-reports } \\
\text { - Self-reports }\end{array}$ & $\begin{array}{l}\text { - Perceived knowledge acquisition, } \\
\text { personal skills, critical thinking42 } \\
\text { - Problem-solving, clinical reasoning }{ }^{40} \\
\text { - } \text { Confidence in performing nursing } \\
\text { care, clinical competencies } 39,41 \\
\text { - Perceived self-confidence } 3,40,42 \\
\text { - } \text { Observed self-stress management, } \\
\text { affective skills } \\
\text { - Perceived professional solidarity }{ }^{42} \\
\text { - Perceived communication skills }{ }^{39} \\
\text { - Perceived mutual support, role } \\
\text { respect in intra-teams }\end{array}$ \\
\hline Medicine & $\begin{array}{l}\text { - Undergraduate } \\
\text { - Undergraduate, } \\
\text { graduate } \\
\text { - Graduate } \\
\text { - Undergraduate } \\
\text { - Undergraduate } \\
\text { - Undergraduate }\end{array}$ & $\begin{array}{l}\text { - Valid assessment } \\
\text { - Valid assessment } \\
\text { - Self-reports } \\
\text { - Self-reports } \\
\text { - Valid assessment } \\
\text { - Valid assessment }\end{array}$ & $\begin{array}{l}\text { - Observed professional knowledge } \\
\text { acquisition, critical thinking 5,33,43,44 } \\
\text { - Observed long-term knowledge } \\
\text { retention }{ }^{5,43} \\
\text { - Perceived knowledge }{ }^{45} \\
\text { - Perceived communication skills } \\
\text { - Observed psychomotor skills } \\
\text { - Observed confidence in applying } \\
\text { skills to clinical situations }{ }^{5}\end{array}$ \\
\hline Pharmacy & $\begin{array}{l}\text { - Graduate, } \\
\text { - Undergraduate, } \\
\text { graduate } \\
\text { - Graduate } \\
\text { - Undergraduate, } \\
\text { graduate } \\
\text { - Graduate }\end{array}$ & $\begin{array}{l}\text { - Valid assessment } \\
\text { - Valid assessment } \\
\text { - Valid assessment } \\
\text { - Self-reports } \\
\text { - Self-reports }\end{array}$ & $\begin{array}{l}\text { - Observed professional knowledge } \\
\text { acquisition, critical thinking, problem- } \\
\text { solving } 10,46 \\
\text { - Knowledge retention } \\
\\
\text { - } \text { Observed confidence in skill } \\
\text { application }{ }^{2,9,10} \\
\text { - Perceived confidence in managing } \\
\text { physiological changes in simulated } \\
\text { patients } 2,9,10 \\
\text { - Perceived reduced anxiety9 }\end{array}$ \\
\hline Occupational Therapy & $\begin{array}{l}\text { - Graduate } \\
\text { - Graduate }\end{array}$ & $\begin{array}{l}\text { - Self-reports } \\
\text { - Self-reports }\end{array}$ & $\begin{array}{l}\text { - Perceived professional knowledge } \\
\text { acqusition }{ }^{47} \\
\text { - Perceived confidence, comfort level } \\
\text { in clinical practice } 47\end{array}$ \\
\hline
\end{tabular}




\begin{tabular}{|c|c|c|c|}
\hline Profession-specific Students & - Type of Program & - Type of Measurement & - Personal-professional competencies \\
\hline Physical Therapy & $\begin{array}{l}\text { - Undergraduate } \\
\text { - Graduate } \\
\text { - Graduate } \\
\text { - Undergraduate, } \\
\text { graduate }\end{array}$ & $\begin{array}{l}\text { - Valid assessment } \\
\text { - Self-reports } \\
\text { - Self-reports } \\
\text { - Self-reports }\end{array}$ & $\begin{array}{l}\text { - Observed clinical physical therapy } \\
\text { competency in supervised clinical } \\
\text { practice } \\
\text { - Perceived professional knowledge of } \\
\text { clinical care, clinical reasoning, } \\
\text { problem-solving } \\
\text { - Perceived confidence/self-efficacy in } \\
\text { supervised clinical practice } \\
\text { - Perceived ability to manage } \\
\text { multitasks }\end{array}$ \\
\hline Dietetics & $\begin{array}{l}\text { - Graduate } \\
\text { - Graduate }\end{array}$ & $\begin{array}{l}\text { - Self-reports } \\
\text { - Self-reports }\end{array}$ & $\begin{array}{l}\text { - Perceived self-efficacy in managing } \\
\text { simulated clinical situations }{ }^{49} \\
\text { - Perceived self-confidence in } \\
\text { performance during supervised } \\
\text { clinical practice }\end{array}$ \\
\hline
\end{tabular}

High-Fidelity Simulations Boost Health Students' Collaborative Competencies in Interprofessional Milieus

Recent studies have suggested that HFS can also be adapted to learning environments in which interprofessional, multidisciplinary teams learn and practice IPEC core competencies. ${ }^{15}$ Because multidisciplinary teams involve different health professionals, the effect of HFS on student achievement in each core competency will be discussed separately. As the majority of studies investigated the impact of HFS on students from two professions, findings will be presented within each competency according to the number of professional programs from which students were drawn in an ascending manner. To avoid repetition, studies that were described in detail earlier in this review will focus on findings that supported the IPEC competencies rather than on the simulation scenarios themselves.

\section{Competency 1: "Values/Ethics for Interprofessional Practice"}

At Widener University, PA, 151 graduate physical therapy and nursing students engaged in a 45-minute simulation of a patient who had to get out of bed with an intravenous line chest tube, urinary catheter, and a nasal cannula. ${ }^{23}$ Students rated their perceptions on three valid surveys: the Interdisciplinary Education Perception Scale (IEPS), which measured attitudes on students' ability to collaborate with teams; the Readiness for Interprofessional Learning Scale (RIPLS), which assessed changes in attitudes arising from participation in IP collaborative practice; and the Attitudes Toward Health Care Teams Scale (ATHCTS), which assessed effective collaboration. A two-by-two repeated measures ANOVA analysis was used to examine student responses on the IEPS, RIPLS, and the ATHCTS followed by post-hoc analysis of Tukey's honestly significant difference test. The level of statistical significance was set at $p<.05$. Post simulation, students strengthened their perceived team-shared values by $10 \%$, as evidenced by an increase from 47.0 to 51.8 , in their pretest-posttest mean scores on a six-point IPEC scale, e.g., "Understanding others' values." Students also improved their perception of team value by $12 \%$ on the ATHCTS scale. The authors concluded that HFS helped students from different professions become a cohesive group within a climate of mutual respect and shared values, thereby establishing a foundation for gaining other IPEC competencies.

At Louisiana State University, LA, 66 undergraduate medical, nursing, and nurse anesthetist students participated in two 2-hour simulations involving two patients: a patient with a life-threatening intra-abdominal hemorrhage due to a stab wound, and a patient with local anesthetic toxicity from a regional upper arm block. ${ }^{50}$ Students self-reported about their team values on the University of Washington Team Assessment Surveys (TAS) scale that exhibited validity in an earlier study. Pretest-posttest mean scores were analyzed using a $t$-test. Mean scores of observer ratings of team performance in two scenarios were analyzed using one-way ANOVA and a t-test at $p<.05$ significance level. Post intervention, students improved their perceived team cohesion (for example, "[I] use strategies effectively to promote team cohesion and effective work interactions") as indicated by a $15 \%$ increase from 3.92 to 4.52 pretest-posttest mean scores on a five-point Likert scale. Observers' rating verified the achievement of Competency 1 , as assessed by a $39 \%$ increase from 1.96 to 4.68 mean scores for students' development of a shared model on the TAS. The authors argued that that HFS could support students' positive attitudes toward team-based training.

(C) The Internet Journal of Allied Health Sciences and Practice, 2019 
Sixty undergraduate medical, nursing, nurse anesthetist, and physical therapy students at Indiana State University, IN, participated in two 2-hour HFS scenarios involving a patient with irregular heart rate and low blood pressure, and a patient with air around the lungs leading to low blood flow to the heart. ${ }^{14}$ Outcomes measured included students' subjective rating and objective, observerbased evaluation on the TAS scale using paired $t$-tests at $p<.05$ significance level. Post intervention, students had improved their ability to create a shared mental model, as designated by an $18 \%$ increase from 4.76 to 5.62 mean scores of peer evaluations from one simulation to the next on the six-point TAS instrument. Seven faculty evaluators reaffirmed students' achievement by noting a $67 \%$ increase from 2.95 to 4.92 in mean scores for the students' shared mental model using the same TAS instrument. Together, the results reflected both perceived and actual development of a shared mental model in a climate of mutual values/ethics with retention over time-a prerequisite for achieving Competency 2.

\section{Competency 2: "Roles and Responsibilities"}

At the University of Kansas, KS, 87.5\% $(n=48)$ of undergraduate dietetic and nursing students who participated in HFS scenarios stated that they learned to respect one another's roles. ${ }^{51}$ Students engaged in three HFS sessions on managing a paraplegic 60 year-old patient who had experienced a motor vehicle accident and was admitted with aspiration pneumonia, a 26 -year-old patient with newly diagnosed Type I DM who was admitted to the ICU with diabetic ketoacidosis, and a 70-year-old female patient with ischemic bowel. Students reported on roles of health professions on pretest-posttest questionnaires that exhibited content validity using the Wilcoxon signed ranks test, but the difference was not statistically significant. Role rotation allowed the nursing students to learn and report more knowledge about dietitians' roles and vice versa. Eighty-eight percent $(n=14)$ of the dietetics students reported in their free-text responses that the HFS sessions helped them learn the roles of other health professionals and $94 \%$ ( $n$ = 52) of them learned to appreciate the value of IP teamwork. The results demonstrated that HFS allowed students "to interact with other healthcare professionals and practice delivering clinical care in a safe environment. ${ }^{51(p 27)}$

Luctkar-Flude et al found similar results in 104 undergraduate fourth-year medical and nursing students at Queen's University, Canada. ${ }^{22}$ Students participated in three 2-hour HFS resuscitation scenarios, with different patients who experienced cardiacrelated conditions intended to clarify the various team roles through rotation of roles. Using the valid Office of Interprofessional Education and Practice (OIPEP) scale, students perceived high confidence in resuscitation skills and reported that the cardiac resuscitation rounds enabled them to learn from one another following simulations. Students had improved their understanding of "seeing points of views" and of "a different profession's roles while learning from one another" in resuscitation, as assessed by their pretest-posttest measures on the Communication and Teamwork Scale of the West of England, Bristol Entry Level Interprofessional Questionnaire. Responses were analyzed using independent sample $t$-tests for interval data and the MannWhitney $\mathrm{U}$ test at $p<.05$ significance level for ordinal data for group comparisons; content analysis was conducted for qualitative responses. The use of simulation-based learning also provided a didactic platform to measure learner ongoing performance.

At the University of Alabama Birmingham, AL, 100 undergraduate medical and nursing students took part in four 20-minute HFS sessions..$^{53}$ The simulations occurred in a simulated emergency room in internal medicine and included patients with acute myocardial infarction, pancreatitis with hyperkalemia, upper gastrointestinal bleeding, and chronic COPD exacerbation. Using the validated Self-Efficacy Scale related to professional roles, students clarified their roles and improved their perceived understanding of each profession's role, as indicated by increases of 4.8 points and 4.9 points in posttest mean scores, respectively, for the medical and nursing students on a newly developed self-efficacy scale. An example of self-efficacy scale included the observation that "multidisciplinary care, where each team member is responsible for their area of expertise, is more productive than crossintegrated care where roles are less defined." "53(p190) Nursing students also reported the greatest improvement in figuring out each other's roles, as indicated by the difference between their pretest-posttest measures $(\Delta=1.1)$. All comparisons were conducted using two-tailed paired $t$-tests at $p<.05$ significance level.

Simko et al obtained similar findings among 60 graduate nursing and pharmacy students in an IP pain education course at Duquesne University, PA. ${ }^{54}$ Students participated in three HFS scenarios involving a patient with $65 \%$ total surface area burn, a patient with low back pain suffering from an ischemic stroke, and a patient with sickle cell crisis. Using a valid Collaboration and Satisfaction about Care Decisions (CSACD) scale measuring self-reported statements of knowledge and importance of professional roles, $59 \%(n=13)$ of the pharmacy students reported improvement in understanding their roles in pain management; nursing students reported similar results (for example, "I know the role of a registered nurse in pain management"), as assessed by the Interprofessional Education Perception Scale (IEPS). Fifty-three percent $(n=17)$ of the nursing students also improved their knowledge of the pharmacist's role. Students' responses were analyzed using two-tailed independent sample $t$-tests at $p<.05$ level of significance.

Paige et al reaffirmed the impact of HFS activities on IP role recognition in 66 undergraduate medical, nursing, and nurse anesthesia students at Louisiana State University, LA. ${ }^{50}$ Upon completion of two 2-hour HFS activities, students improved

(c) The Internet Journal of Allied Health Sciences and Practice, 2019 
understanding of their role and that of other team members. There was a $15 \%$ increase from 3.89 to 4.48 in pretest-posttest mean scores as rated by trained observers on the validated Operating Room Teamwork Assessment Surgery scale (ORTAS) using independent sample $t$-tests at $p<.05$ level of significance. Students also reported that role rotation within their profession during the simulation helped them "know clearly the task responsibilities of each team member," as assessed on a self-efficacy five-point Likert questionnaire.

At the University of Oslo, Norway, 165 undergraduate medical, nursing, and nurse anesthesia students took part in four 20-minute HFS sessions relating to different trauma levels of a patient in the emergency room..$^{55}$ Post simulations, students had demonstrated role recognition and learned to adhere to their role while becoming proactive in their role (e.g., "I reflected on how much a nurse can prepare and make ready in advance") as assessed by 16 observers' qualitative evaluations. In their free-text responses, nurse anesthesia students reported the highest level of comfort. A Kruskal-Wallis test was used to determine if there were differences between students with different professions and pairwise comparisons using a Bonferroni adjustment for multiple comparisons. Statistical significance was set up for $p<0.05$.

King et al found a similar trend among 56 students in undergraduate nursing, physical therapy, and respiratory therapy programs at the University of Ottawa, Canada. ${ }^{4}$ Post one-hour HFS on a male patient, who suffered from COPD and recovered from a surgical repair of a hip fracture, students had improved their perceived understanding of other professions' roles to work together, as assessed by their pretest-posttest responses on the validated Interprofessional Collaborative Competencies Attainment Survey (ICCAS). Interprofessional Education Collaborative competencies on the ICCAS survey were analyzed using a paired $t$-test at $p<$ 0.05 significance level. Students' perceptions on their roles in a team and their own function during the scenario session were measured by an open-ended questionnaire that achieved content validity and was analyzed using a descriptive content analysis. Students reported that HFS provided them the "opportunity to better understand the roles of other healthcare professionals in working together to help patients living with respiratory conditions."4(p604)

Titzer et al explored the effect of HFS in 131 students on undergraduate nursing, occupational therapy, radiologic technology, and respiratory therapy programs at the University of Southern Indiana, IN. ${ }^{56}$ Post simulation on a 56-year-old male with a paralytic ileus and a history of COPD, students acknowledged one another's professional roles, some of which contrasted with their general beliefs, as assessed by the Healthcare Provider Priority Survey (HPPS) qualitative responses. Students also perceived the HFS as an opportunity to support teamwork, collaboration, and problem solving. Together, the findings highlight the effectiveness of HFS on gaining recognition of roles and responsibilities of health students within an IP environment. Acknowledging role recognition is considered a prerequisite for Competency 3.

\section{Competency 3: "Interprofessional Communication"}

At Queen's University, Canada, 104 undergraduate medical and nursing students manifested proficiency in IP communication in HFS resuscitation scenarios on a simulated patient who experienced different cardiac conditions. ${ }^{52}$ Post simulation, students reported improvement in their comfort with IP communication within their team, as measured by a total mean score of 51.56 out of 54.00 on the Communication and Teamwork Scale of the West of England, Bristol Entry Level Interprofessional Questionnaire. Students reported feeling comfortable learning with students from other professions as demonstrated in their statements, e.g., "[l feel] comfortable working in groups" or "[ feel] comfortable expressing opinions in a group, even when I know that other people don't agree with them]." Students also stated that they gained confidence in performing cardiac resuscitation skills.

Tofil et al found that 100 medical and nursing students at the University of Alabama Birmingham, who participated in four 20-minute HFS scenarios in a simulated emergency room, improved their communication skills. ${ }^{53}$ There were $25 \%$ increases in self-efficacy communication mean scores from 18.9 to 23.7 and from 19.6 to 24.5 , respectively, using two-tailed paired $t$-tests at $p<.05$ significance level for the medical and nursing students on a self-efficacy scale. Medical students also showed marked improvement in their confidence to close the loop in communication even when it slowed patient care $(\Delta=0.93)$. At King's College, U.K., 271 undergraduate medical and nursing/midwifery students demonstrated similar results. ${ }^{57}$ Students participated in six 15-minute HFS scenarios; five entailed acute illness and one involved communication. There was an increase of $15.5 \%$ in communication skills in nursing students. Students also improved their perceived understanding of linking communication skills and clinical outcomes, as assessed by their free-text responses on a self-efficacy and communication scale. Medical students reported that IP HFS training improved their communication skills.

Bolesta and Chmil showed the impact of HFS on 55 undergraduate pharmacy and nursing students at Wilkes University, PA, who completed a 20-minute HFS scenario concerning a patient with acute exacerbation of heart failure. ${ }^{58}$ Post simulation, $67.7 \%(n=$ 42) of the students reported that communication skills were the most important element that they gained in the simulation experience as ranked on the validated Readiness for Interprofessional Learning Scale (RIPLS). Given that data were not normally

(c) The Internet Journal of Allied Health Sciences and Practice, 2019 
distributed for any of the results, the Wilcoxon signed-rank test was used at $p<.05$ level of significance level. Students also indicated that the IP HFS helped them think more positively about students from other professions and become team members.

George found that $93.8 \%(n=52)$ of undergraduate dietetic and nursing students at the University of Kansas, who participated in two 30-minute HFS scenarios reported improved confidence and ability to communicate with other team members, as assessed by their pretest-posttest free-text responses; e.g., "I am confident in my ability to communicate patient care information to other healthcare professionals via face-to-face interactions or on the phone."51(p62) Eighty-eight undergraduate nursing and social worker students at Rhode Island College, RI, participated in a 20-minute HFS activity on a female with a history of dementia, who suffered from a urinary infection, reported improved perceived IP communication skills and readiness to collaborate with the team, as indicated in their pretest-posttest open-ended responses. ${ }^{58}$

Paige et al examined the effect of HFS on 66 medical, nursing, and nurse anesthesia students at Louisiana State University. ${ }^{50}$ After completing two HFS sessions, students improved their self-efficacy for adaptive communication skills, as indicated by an increase from 4.05 to 4.61 mean scores on their pretest-posttest questionnaire on a self-efficacy six-point Likert scale. Students were able to "use specific communication strategies to confirm that messages are received and the content is accurately understood (for example, closed-loop communication)." 50 (p143) They supported their self-rating by free-text responses including "emphasizing that communication between team members... made me realize where my faults as a team leader can be improved"; and "[Practitioners in each discipline should] recognize the importance of introducing themselves and using each other's names." This finding corresponded to similar adaptive communication ratings of evaluators on the Operating Room Teamwork Assessment Surgery scale (ORTAS), suggesting that IP communication was a prerequisite for team-based behaviors. Jakobsen et al also showed that 165 undergraduate medical, nursing, and nurse anesthesia students at the University of Oslo, Norway, who participated in four 20-minute HFS scenarios had improved their communication skills, as assessed by a $14 \%$ increase from their 4.4 to 5.0 mean scores on a pretest-posttest five-point Likert scale. 55 Students' free-text responses to open-ended questions confirmed the positive impact of HFS; e.g., "closed-loop communication" through unambiguous messages from team members or active listening to patients and team members. Students could also identify the effect of poor communication (for example, "I experienced in the simulations that unclear messages/communication lead to poor teamwork") and ways to prevent it. Students' observed mastery of IP communication skills were further verified by 16 course facilitators, as indicated by a 4.1 mean score on a five-point Likert rating scale.

Improvement in IP communication skills was also demonstrated by Kim et al.59 The authors reported that when 402 medical, nursing, pharmacy, and allied health students at Loma Linda University, CA, participated in three 20-minute HFS sessions, they improved their critical event communications. Engaged in the simulations on patients after a heart attack, or organophosphate poisoning, or bombing injuries, ie, blast bomb-related lung, and traumatic amputation, students improved their perceived IP communication skills as indicated by an $18 \%$ increase from 3.87 to 4.04 mean scores in pretest-posttest measures on the selfreported Loma Linda Interprofessional Education Assessment scale, using the Mann-Whitney tests for data that were not normally distributed, followed by Student's $t$-tests at two-tailed $p<.05$ significance level, and a Bonferroni adjustment for multiple comparisons. Observers found an improvement in communication skills of $5 \%$ to $7 \%$. Students also acknowledged the potential for medical errors due to poor team communication. Improvement in team values and critical event knowledge were also reported.

Garbee et al found that HFS helped 60 medical, nursing, nurse anesthesia, and physical therapy students at Indiana State University improve their communication skills. ${ }^{14}$ Students worked together through two simulation scenarios, involving a patient with irregular heart rate and low blood pressure and a patient with air under the lung leading to low blood flow from the heart. Post simulations, a 16\% increase from 4.92 to 5.72 in adaptive communication mean scores on the TAS instrument was observed and further verified by trained observers on the Communication and Teamwork Skills (CATS) assessment tool using a paired $t$-test at $p<.05$ significance level. Vyas et al reaffirmed this finding among 210 undergraduate and graduate medical, nursing, pharmacy, and health administrator students at the University of Missouri-Kansas, MO.60 Students completed five HFS scenarios on an asthmatic male, an 11-month-old male infant with head trauma, a pregnant female with nausea and vomiting, a male with a wrist pain, and a male with a chest pain. Using a 10-point Team Building and Interprofessional Communications Survey, responses were analyzed using the Wilcoxon signed rank test to compare the distribution of each survey question pre- and post-simulation at $p<.05$ significance level. Post simulations, students reported improved IP communication, as indicated by a $7 \%$ increase from 7.7 to 8.2 pretest-posttest mean scores on a 10-point Team Building and Interprofessional Communications Survey. An example of a response included "I am comfortable communicating with individuals from other healthcare professions." Over $90 \%$ of the students agreed that HFS reinforced their appreciation to the value of IP communication in teamwork. Students also reported improved knowledge and IP skills.

(c) The Internet Journal of Allied Health Sciences and Practice, 2019 


\section{Competency 4: "Teams and Teamwork"}

Evidence indicates that teamwork is the focal point at which mutual respect and values, role and responsibilities, and IP communication converge. In particular, communication and teamwork can be viewed as interdependent in that communication skills are necessary to establish teamwork, while teamwork might promote effective IP communication. ${ }^{51,52}$ Watters et al exemplified the effect of HFS on communication-teamwork interdependencies in 271 undergraduate medical and nursing students at King's College, U.K., who participated in six 15-minute HFS activities. ${ }^{57}$ Using the Self-efficacy and Communication Scale (SECS) that achieved face and high content validity, students reported an enhanced understanding of the communication-teamwork overlap using a paired $t$-test at $p<.05$ significance level. Sometimes students acknowledged communication as indispensable to effective teamwork; at other times, teamwork was viewed as a vehicle to achieve successful IP communication. Students reported improved confidence in team leadership and management skills, as assessed by their self-report pretest-posttest measures on SECS. Observed ratings of medical students showed that IP training was associated with better final outcomes for communication and team behaviors. Brashers et al examined the influence of HFS on team skills and collaborative behaviors in 458 undergraduate medical and nursing students at the University of Virginia, VA. ${ }^{61}$ Students engaged in four HFS scenarios, involving family meetings, a patient with sepsis, a pediatric patient, and an elderly patient with dementia. Post simulation, students reported a $3 \%$ increased improvement in their team skills on the Team Skills Scale (TSS) using Wilcoxon signed ranks tests to assess the percent change in students' TSS scores. A 4.5\% increase in team discussion and collaborative behaviors mean scores on the Collaborative Behaviors Observational Assessment Tools (CBOAT) was reported using the nonparametric analysis of Wilcoxon signed ranks and Mann-Whitney at $p<.05$ to compare the responses of medical and nursing students. Trained providers rated students' teambased behaviors on the Interprofessional Teamwork Objective Structured Clinical Examinations (ITOSCEs) by similar improvement percentages, confirming students' observed improvement in clinical team-based skills.

Garbee et al found that 60 medical, nursing, nurse anesthesia, and physical therapy students at Indiana State University, who participated in two HFS sessions improved their team-based performance from 4.31 to 4.95 pretest-posttest mean scores on the TAS instrument as rated by observers. ${ }^{14}$ Improvements were also observed in team coordination and situation monitoring. When 66 nursing, nurse anesthesia, and medical students at Louisiana State University participated in HFS team training, they also improved their team-based behaviors by $64 \%$ from 2.42 to 3.98 mean scores as assessed by observers. ${ }^{50} \mathrm{Kim}$ et al confirmed previous results in a study on 402 medical, nursing, pharmacy, and allied health students at Loma Linda University who participated in eight HFS sessions. ${ }^{59}$ Post simulation, students improved three team-based behaviors on the self-reported Loma Linda Interprofessional Education Assessment scale. In particular, students improved one another's contribution to the team by $24 \%$, monitoring situation skills by $6 \%$ ("lt is important to monitor the emotional and physical status of other team members"), and working with teams by $15 \%$ ("A team's mission is of greater value than the goals of individual team members").

Similarly, 118 students in undergraduate and graduate medical laboratory, respiratory therapy, radiology therapy, and diagnostic cytology/genetics at the University of Toronto, Canada, participated in HFS activities involving diverse patient care scenarios. ${ }^{13}$ Post simulations, $96 \%(n=113)$ of them improved their ability to work in teams, resolve conflict, and reach decisions collaboratively, as indicated by an observed 3.56 mean score rated by clinical evaluators on a five-point Clinical Coordinator Online Survey using a one-way ANOVA tested for differences in clinical educator responses across the four academic programs studied. Students' responses were analyzed using paired and independent sample $t$-tests to detect changes from simulation to mid-clinical at $p<.05$ significance level. Post HFS, students reported that HFS fostered a sense of collective responsibility, accountability, and professionalism, as indicated by changes from simulation to mid-clinical practicum.

At Widener University, PA, 151 undergraduate physical therapy and nursing students completed a 45-minute HFS activity and its evlaution. ${ }^{23}$ Post simulation, students reported improved teamwork shown by a $6 \%$ increase from 40.9 to 43.6 on their pretestposttest mean scores on the RIPLS using repeated measures ANOVA analysis at $p<.05$ significance level. The simulation activities also enhanced students' self-reflection and deepened their understanding of the need for IP cooperation, as assessed by a $7 \%$ increase from 63.4 to 67.9 in their attitudinal survey mean scores. This result confirmed the finding in Meyer et al who showed that HFS improved students' perceived conviction of the value of teamwork among 146 undergraduate pharmacy and nursing students at South Dakota University, SD. ${ }^{21}$ Data were analyzed using a two-sample $t$-test to compare the scores. Together, the findings show that HFS promote students' mastery of all IPEC competencies within an IP learning environment. Table 2 summarizes the effect of HFS on the students' gain of each of the four interprofessional competencies matched to type of program and measurement type in interprofessional milieus.

(c) The Internet Journal of Allied Health Sciences and Practice, 2019 
Table 2. Students' Gain of Interprofessional Competencies Matched to Type of Measurement through High-Fidelity Simulations

\begin{tabular}{|c|c|c|c|}
\hline IPEC core competencies & Type of program & Type of measurement & Interprofessional competencies \\
\hline $\begin{array}{l}\text { Values and Ethics for } \\
\text { Interprofessional Practice }\end{array}$ & $\begin{array}{l}\text { - Graduate } \\
\text { - Undergraduate } \\
\text { - Undergraduate }\end{array}$ & $\begin{array}{l}\text { - Self-reports } \\
\text { - Self-reports } \\
\text { - Valid assessment } \\
\text { - Self-reports } \\
\text { - Valid assessment }\end{array}$ & $\begin{array}{l}\text { - Strengthened perceived team shared } \\
\text { values within a climate of mutual } \\
\text { respect }{ }^{23} \\
\text { - Perceived team cohesion, } \\
\text { development of a shared model }{ }^{50} \\
\text { - Created a shared mental model }{ }^{14}\end{array}$ \\
\hline Roles and Responsibilities & $\begin{array}{l}\text { - Undergraduate } \\
\text { - Undergraduate, } \\
\text { graduate } \\
\text { - Undergraduate } \\
\text { - Undergraduate }\end{array}$ & $\begin{array}{l}\text { - Self-reports } \\
\text { - Valid assessment } \\
\text { - Self-reports } \\
\text { - Valid assessment } \\
\text { - Self-reports } \\
\text { - Self-reports }\end{array}$ & $\begin{array}{l}\text { - Learned the roles of other health } \\
\text { professional, valued of } \\
\text { interprofessional teamwork }{ }^{51} \\
\text { - Understood one's role, recognized } \\
\text { professional roles of others, and } \\
\text { perceived comfort in teamwrok } 51-54 \\
\text { - Perceived understanding of other } \\
\text { professions' roles } \\
\text { - Acknowledged one another's } \\
\text { professional roles contrasted with their } \\
\text { general beliefs } 56\end{array}$ \\
\hline $\begin{array}{l}\text { Interprofessional } \\
\text { Communication }\end{array}$ & $\begin{array}{l}\text { - Undergraduate } \\
\text { - Undergraduate } \\
\text { - Undergraduate } \\
\text { - Undergraduate } \\
\text { - Undergraduate } \\
\text { - Undergraduate } \\
\text { - Undergraduate } \\
\text { - Undergraduate }\end{array}$ & $\begin{array}{l}\text { - Self-reports } \\
\text { - Self-reports } \\
\text { - Self-reports } \\
\text { - Self-reports } \\
\text { - Self-reports } \\
\text { - Self-reports } \\
\text { - Valid assessment } \\
\text { - Self-reports } \\
\text { - Valid assessment } \\
\text { - Self-reports } \\
\text { - Valid assessment }\end{array}$ & $\begin{array}{l}\text { - Perceived comfort with team } \\
\text { interprofessional communication }{ }^{51,60} \\
\text { - Improved perceived communication } \\
\text { skills } 53,57 \\
\text { - Perceived understanding of linking } \\
\text { communication skills and clinical } \\
\text { outcomes } \\
\text { - Perceived communication skills were } \\
\text { the most important element gained } 53 \\
\text { - Perceived closed-loop communication, } \\
\text { confirmed receiving accurate } \\
\text { messages } \\
\text { - Perceived active listening to patients } \\
\text { and team members, identified the } \\
\text { effect poor communication } \\
\text { - Improved perceived IP communication, } \\
\text { acknowledged the potential for medical } \\
\text { errors due to poor communication }{ }^{59} \\
\text { - Improved adaptive IP } \\
\text { communication }{ }^{14,50}\end{array}$ \\
\hline
\end{tabular}




\begin{tabular}{|c|c|c|c|}
\hline IPEC core competencies & - Type of program & - Type of measurement & - Interprofessional competencies \\
\hline Teams and Teamwork & $\begin{array}{l}\text { - Undergraduate } \\
\text { - Undergraduate } \\
\text { - Undergraduate } \\
\text { - Undergraduate } \\
\text { - Undergraduate, } \\
\text { graduate } \\
\text { - Undergraduate }\end{array}$ & $\begin{array}{l}\text { - Self-reports } \\
\text { - Self-reports } \\
\text { - Valid assessment } \\
\text { - Self-reports } \\
\text { - Valid assessment } \\
\text { - Self-reports } \\
\text { - Valid assessment } \\
\text { - Valid assessment } \\
\text { - Self-reports } \\
\text { - Self-renorts }\end{array}$ & 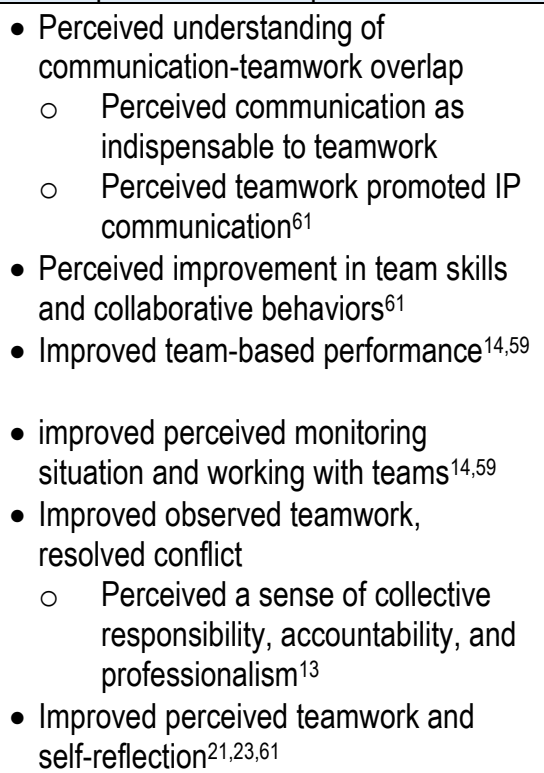 \\
\hline
\end{tabular}

\section{CONCLUSIONS}

High-fidelity simulation instruction is an effective method to help health professional students achieve profession-specific and IP competencies in a safe learning environment. 13,14 Students can make mistakes, correct them, and learn from them in real time, without compromising patient safety. The purpose of this review was to summarize the literature related to HFS methods that promoted the achievement of various student competencies in profession-specific and IP health environments. This review of the literature revealed that HFS enhanced students' cognitive, affective, and autonomous clinical skills in intraprofessional learning milieus. ${ }^{62}$ High-fidelity simulations within profession-specific settings promoted knowledge acquisition, clinical reasoning, and selfconfidence in performing clinical skills. ${ }^{38}$ One could deduce that HFS could replace part of clinical practice in profession-specific environments, as confirmed by Hayden et al. ${ }^{62}$ In their comprehensive review, the authors found that when HFS replaced clinical experience in a nursing program, educational outcomes were equivalent to $50 \%$ of traditional clinical experience.

The findings of this review indicated similarities and differences in students' personal competencies. Nursing, medical, pharmacy, occupational therapy, and physical therapy students perceived gains in personal-professional competencies following HFS regardless of their profession specialization. Other health professional students also improved their perceived self-confidence in using clinical skills within an HFS learning environment. The simulation also facilitated gains in perceived communication skills of students across professions. Nursing students perceived gains in professional solidarity and mutual support, while physical therapy students gained a perceived ability to manage multitasks. High-fidelity simulations also promoted actual personal competencies in a profession-specific environment. Medical and pharmacy students also gained observed knowledge retention and confidence in skill application following HFS sessions. Medical, pharmacy, and physical therapy students gained observed knowledge acquisition and clinical skills, whereas nursing students gained observed self-stress management competencies following HFS.

Differences also appear in the type of measurement used to collect data on students' personal competencies following HFS learning. Of 22 studies, findings of six studies relied on data collected through valid assessment instruments, while 16 studies reported results that were based on students' self-reports. This finding suggests a varying degree of the quality of evidence. Almost half of the studies used sound research design and unbiased assessment, indicating a moderate to strong strength of evidence that increases confidence in the studies' findings.

By and large, high-fidelity mannequin simulation facilitated the accomplishment of personal, cognitive, and affective competencies and some aspects of clinical skills. Likewise, high-fidelity mannequin simulation can develop limited team-based skills within intraprofessional milieus. Nursing and medical students developed interpersonal communication skills and role respect, promoting their profession-specific solidarity. In this way, high-fidelity mannequin simulation prepares students to acquire collaborative skills to work with other health professionals in IP environments, signifying the effectiveness of HFS as a learning technique.

(C) The Internet Journal of Allied Health Sciences and Practice, 2019 
Within an IP learning environment, HFS helped students develop collaborative, team-based skills. ${ }^{14,61}$ Students increased their understanding of the value of mutually respecting one another's professional roles as a foundation for developing IP communication abilities, which, in turn, promoted IP team building. The findings of this review suggest that HFS is a suitable method to help students achieve all the four IP core competencies in that developing mutual respect (Competency 1) forms a foundation for acknowledging one another's roles while recognizing one's professional limitations (Competency 2). Interprofessional communication (Competency 3) aims to enhance effective teams and teamwork (Competency 4). In general, the findings suggest that HFS in an IP environment can motivate students to accomplish the four IPEC core competencies.

The findings also support the notion that HFS instruction offers a method for developing IP team-based collaboration, e.g., in monitoring situations or assisting with tasks. These benefits reflect the Team STEPPS framework, which is designed to optimize team performance across healthcare professions and delivery systems. ${ }^{54}$ Indeed, high-fidelity mannequin simulation provides a model for gaining other Team STEPPS skills, e.g., situation awareness, cross-monitoring, mutual support, and effective communication skills. Whether HFS activities can promote all Team STEPPS skills remains unclear.

The review of the literature reveals that HFS promotes both profession-specific and IP competencies across undergraduate or graduate programs. Within a profession-specific environment, nursing and medical students gained personal and professionspecific competencies following HFS in the second- to fourth-year in undergraduate programs. In pharmacy, occupational therapy, and dietetics programs, HFS facilitated students' gain of personal competencies in graduate programs. Within an IP milieu, students who gained IP competencies were in undergraduate programs. Within an IP environment, $84 \%(n=16)$ of the studies involved undergraduate students, while $16 \%(n=3)$ of studies included graduate students. These findings suggest that the type of competencies students can gain is determined by the learning milieu, profession-specific or IP, rather than the program type. In this respect, high-fidelity simulation can be considered as a paradigm to improve both personal and IP competencies of students at an early stage of their undergraduate professional education and be strengthened in their graduate programs; a consideration that is also supported by Paige. ${ }^{00}$ The author argued that the integration of HFS team training into the programs' curricula 'could provide the opportunity for undergraduate senior students to learn critical team-based competencies that, with reinforcement in graduate training and clinical practice, could culture a team-oriented view."50(p147) Together, the findings suggest that HFS can be used across types of programs, increasing the merit of developing similar educational experiences in other health professions.

This review also unveils that different competencies can be gained in HFS learning and can complement conventional (lecturebased) instruction: whereas conventional instruction allows for immediate gain in knowledge and technical skills in intraprofessional environments, HFS enhances long-term knowledge retention and development of IP competencies. 5,9,10,33,60,63,64 This suggestion was also confirmed by Boet et al who found that a single high-fidelity simulation training session along with practice and feedback improved cricothyroidotomy procedural skills that were retained for at least one year. ${ }^{64}$ Thus, high-fidelity mannequin simulation may be viewed as a two-stage learning paradigm in which simulations first enhance personal competencies, for example, knowledge acquisition, technical skills, and self-confidence in a simulated clinical environment. Built on the professional knowledge and confidence, in the second stage, HFS serves as a foundation for IP team-based functioning within IP environments. 65 While simulation has been used to develop participants' knowledge and skills in performing technical tasks, increasingly it is used also as a setting for developing teamwork and communication in a safe environment. Crea argued that learning through classroom courses is only the first step for students in developing knowledge, experience, and competence, whereas HFS is seen as a medium to achieve clinical competency in a safe environment. ${ }^{5}$ This assertion was supported by White et al who suggested that only a combination of traditional classroom lecture, interactive teaching methods, and HFS is the most effective approach to gain cognitive skills, self-confidence, and clinical competence. ${ }^{66}$ Laschinger et al further argued that simulation should be an adjunct for clinical practice, not a replacement, as it is a viable didactic platform that can be integrated into the pre-clinical setting. ${ }^{43,67}$

In addition, high-fidelity simulation can be considered a means for improving patient outcomes in that students' ability to transfer knowledge and skills to clinical care improves a patient's health condition, while poor application of knowledge is associated with mismanagement and poor patient outcomes. ${ }^{33}$ The results of Gordon and Buckley support this consideration, as they showed that HFS improved students' perceived technical and nontechnical skills to stabilize patient's deteriorating conditions in simulated clinical emergencies. ${ }^{6}$

This review has several limitations that highlight gaps in the literature. First, approximately half of the findings related to personal competencies relied on subjective, self-reported data that limited their evidence strength. Second, $23 \%(n=10)$ of the data were collected using instruments that lack construct validity, which limited confidence in the study results. Third, $19 \%(n=8)$ of the studies included small sample sizes that could increase the occurrence of type-I and type-II errors that falsely reject or accept hypotheses..$^{63}$ Lewis et al suggested that smaller sample sizes could compensate by both the richness of the data and the use of mixed methods approaches, which applied in the studies cited above. ${ }^{19}$ One could deduce that these limitations were due to a lack

(c) The Internet Journal of Allied Health Sciences and Practice, 2019 
in any existing standardized instruments to assess students' competencies across different health professions. ${ }^{47,49}$ Fourth, $44 \%$ (n $=15$ ) of the studies used nonparametric tests, which are less powerful than parametric tests, and their strength of evidence is reduced. ${ }^{25}$ Fifth, $50 \%(n=11)$ of the studies were built on a less sound research design and showed limited evidential strength due to students' self-reported perceptions of gain in personal competencies, leading to a response bias that limits confidence in the study's results. ${ }^{69}$ Nevertheless, the findings underline the use of HFS to benefit health professions learners in the U.S. and other countries across simulation scenarios and differences in measurement instruments.

As a preliminary review of the literature, this article contributes to our understanding of the significance of HFS in promoting the achievement of diverse competencies among health students. Accordingly, the following recommendations for future research and education are proposed.

\section{RECOMMENDATIONS}

1. Validate new, better instruments that measure students' perceived competencies following HFS.

2. Create a new observer rating scale to assess students' acquisition of profession-specific and IP competencies following HFS.

3. Incorporate HFS activities into undergraduate profession-specific and IP curricula and examine their effects on students' personal and IP competencies.

4. Incorporate HFS activities into graduate IP curriculum and examine their effects on students' personal and IP competencies.

5. Investigate whether HFS activities can replace clinical practice.

6. Increase the number of HFS activities related to all IPEC competencies to solidify students' team-based skills.

\section{REFERENCES}

1. World Health Organization [WHO]. Transforming and scaling up health professionals' education and training. Geneva, Switzerland: WHO Press; 2013.

http://apps. who.int/iris/bitstream/handle/10665/93635/9789241506502_eng.pdf;jsessionid=8F2739A9B9363BF485476E5D5 1E29DC2? sequence=1 Accessed on September, 25, 2018.

2. Branch C. Pharmacy students' learning and satisfaction with high-fidelity simulation to teach drug-induced dyspepsia. AJPE. 2013;77(2):Article 30. [PMID: 23519773].

3. Tosterud R, Hedelin B, Hall-Lord ML. Nursing students' perceptions of high-fidelity simulation used as learning methods. Nurse Educ Pract. 2013;13(4):262-270. [PMID: 23454066].

4. King J, Beanlands S, Fiset V, et al. Using interprofessional simulation to improve collaborative competences for nursing, physiotherapy, and respiratory therapy students. J Interprof Care. 2016;30(5):599-606. [PMID: 27340933].

5. Nimbalkar A, Patel D, Phatak A, Vasa R. Randomized control trial of high-fidelity vs. low-fidelity simulation for training undergraduate students in neonatal resuscitation. BMC Res Notes. 2015;8:636-643. [PMID: 26526494].

6. Munshi, F. J., Lababidi, H., \& Alyousef, S. (2015). Low- versus high-fidelity simulations in teaching and assessing clinical skills. J Taibah Univ Sci [Internet]. 2015;0(1):12-15. https://www.sciencedirect.com/science/article/pii/S1658361215000141 Accessed on July $5,2015$.

7. Tun JK, Alinier G, Tang J, Kneebone RL. Redefining simulation fidelity for healthcare education. Simul Gaming. 2015;46(2):159-174. http:///journals.sagepub.com/doi/abs/10.1177/1046878115576103?journalCode=sagb Accessed on July 10, 2018.

8. Can R, Cooper S. Simulation-based learning in education: A systematic review. J Adv Nurs. 2010;66(1):3-15. [PMID: 27902949].

9. Skoy ET, Eukel HN, Frenzel JF. Comparison of low- and high-fidelity simulation to train and assess pharmacy students' injection technique. Am J Pharm Educ. 2013:77(2):Article 33. [PMID: 23518687].

10. Bingham AL, Sen S, Finn LA, Cawley MJ. Retention of advanced cardiac life support knowledge and skills following highfidelity mannequin simulation training. AJPE. 2015;79(1):Article 12. [PMID: 25741028].

11. Meurling L, Lidefelt KJ, Escher C, Felländer-Tsai L, Wallin CJ. Comparison of high- and low equipment fidelity during pediatric simulation team training: A case control study. BMC Med Educ.2014;14:221-229. [PMID: 25326794].

12. Smithburger PL, Kane-Gill SL, Kloet MA, Lohr B, Seybert AL. Advancing interprofessional education through the use of high-fidelity human patient simulators. J Pharm Pract. 2013;11(2):61-65. [PMID: 24155851].

13. Bandali KS, Craig R, Ziv A. Innovations in applied health: Evaluating a simulation-enhanced, interprofessional curriculum. Med Teach. 2012;34(3):176-184. [PMID: 22364474].

(C) The Internet Journal of Allied Health Sciences and Practice, 2019 
14. Garbee DD, Paige JT, Bonanno LS, et al. Effectiveness of teamwork and communication education using interprofessional high-fidelity human patient simulation critical care code. Nurse Educ Pract [Internet]. 2013;3(3);1-12. [cited 2018 May 15]. https://doi.org/10.5430/inep.v3n3p1 Accessed on July 25, 2018.

15. Cato DL, Murray M. Use of simulation training in the intensive care unit. Crit Care Nurs Q. 2010;33(1):44-51. [PMID: 20019509].

16. Miller GE. The assessment of clinical skills/competence/ performance. Acad Med. 1990;65(S9):63-7. [PMID: 2400509].

17. McGaghie WC, Issenberg SB, Cohen ER, Barsuk JH, Wayne DB. Does simulation-based medical education with deliberate practice yield better results than traditional clinical education? A meta-analytic comparative review of evidence. Acad Med. 2011;86:706-711. [PMID: 21512370].

18. Wright A, Moss $P$, Dennis DM, Harrold. The influence of a full-time, immersive simulation-based clinical placement on physiotherapy confidence during transition to clinical practice. Adv Simul. 2018;3:3-13. [PMID: 2948204].

19. Lewis $R$, Strachan $A$, Smith MM. Is high-fidelity simulation the most effective method for the development of non-technical skills in nursing? A review of the current evidence. Open Nurs J. 2012;6:82-89. [PMID: 22893783].

20. Konia M, Yao A. Simulation-a new educational paradigm? J Biomed Res. 2013;27(2):75-80. [PMID: 23554798].

21. Meyer BA, Seefeldt TM, Ngorsuraches S, et al. Interprofessional education in pharmacology using high-fidelity simulation. Curr Pharm Teach Learn. 2017;9(6):1055-1062. [PMID: 29233373].

22. Interprofessional Education Collaborative [IPEC]. Core competencies for interprofessional collaborative practice: 2016 update. Washington, DC: Interprofessional Education Collaborative;2016. https://aamcmeded.global.ssl.fastly.net/production/media/filer_public/70/9f/709fedd7-3c53-492c-b9f0b13715d11cb6/core competencies for_collaborative practice.pdf Accessed on July 2, 2018.

23. Wellmon R, Lefebvre KM, Ferry D. Effects of high-fidelity simulation on physical therapy and nursing students' attitudes toward interprofessional learning and collaboration. J Nurs Educ. 2017;56(8), 456-465. [PMID: 28787067].

24. Azer AS. The top-cited articles in medical education: A bibliometric analysis. Med Educ. 2015;90(8):1-15. https://med.uottawa.ca/epidemiology/sites/med.uottawa.ca.epidemiology/files/the_top_cited_articles_in_medical_education. pdf Accessed on May 26, 2018.

25. Leedy PD, Ormrod JE. Practical research: Planning and design ( $9^{\text {th }}$ ed). Boston, MA: Pearson Education.

26. Shinnick MA, Woo M, Horwich TB, Steadman R. Debriefing: The most important component in simulation? Clin Simul Nurs. 2011;7(3):e105-111. http://www.oclbcp.org/Documents/Simulation\%20articles/Debriefing\%20The\%20Most $\% 20$ Important\%20Component $\% 20$ in $\%$ 20Sim.pdf Accessed on August 10, 2018.

27. Cook JV, Dickinson HO, Eccles MP. Response rates in postal surveys of healthcare professionals between 1996 and 2005: An observational study. BMC Health Serv Res. 2009;9(1):160-168. [PMID: 19751504].

28. Willis GB, Smith T, Lee HJ. Do additional recontacts to increase response rate improve physician survey data quality? Med Care. 2013;51(10):945-948. [PMID: 23969583].

29. Sharma B. A focus on reliability in developmental research through Cronbach's Alpha among medical, dental and paramedical professionals. Asian Pac. J. Health Sci. 2016;3(4):271-278. https://www.apjhs.com/pdf/43-A-focus-onreliability-in-developmental-research-through-Cronbachs-Alpha-among-medical-dental-and-paramedical-professionals.pdf Accessed on August 25, 2018.

30. U. S. Preventive Services Task Force. GRADE definitions after July 2012. https://www.uspreventiveservicestaskforce.org/Page/Name/grade-definitions Updated in February, 2013. Accessed on October 4, 2015.

31. Blum CA, Borglund S, Parcells D. High-fidelity nursing simulation: Impact on student self-confidence and clinical competence. IJNES. 2010;7(1):Article 18. [PMID: 20597857].

32. Bowling AM, Underwood PW. Effect of simulation on knowledge, self-confidence, and skill performance: A quasiexperimental study. Nurs Health Sci. 2016;18(3):292-298. [PMID: 26834000].

33. Cortegiani A, Russotto V, Montalto F, et al. Effect of high-fidelity simulation on medical students' knowledge about advanced life support: A randomized study. PLOS One. 2015:10(5):0125685-0125697. [PMID: 25955760].

34. Moriates C, Dohan D, Spetz J, Sawaya FG. Defining competencies for education in health care value: Recommendations from the University of California, San Francisco Center for Healthcare Value Training Initiative. Acad Med. 2015;90(4):421424. [PMID: 25354077].

35. Frank G, Hubal R, O'Bea M. Using competency definitions to adapt training for a mission. Paper presented in the Interservice/Industrial Training, Simulation, and Education Conference; November 26-29, 2007; Orlando, FL.

36. Harris P, Snell L, Talbot M, Harden RM. Competency-based medical education: implications for undergraduate programs. Med Teach. 2010;32(8):645-650. [PMID: 20662575].

37. Oh PJ, Jeon KD, Koh MS. The effects of simulation-based learning using standardized patients in nursing students: A metaanalysis. Nurse Educ Today. 2015;35(5):e6-e15. [PMID: 25680831].

(C) The Internet Journal of Allied Health Sciences and Practice, 2019 
38. Brien LA, Charette M, Goudreau J. Nursing students' perceptions of the contribution of high-fidelity simulation and clinical placement in a critical care. Clin Simul Nurs [Internet]. 2017:13(9):436-441. https://www.nursingsimulation.org/article/S18761399(17)30034-8/abstract Accessed on July 20, 2018.

39. Young KH, Eun K, Sook LE. Effects of simulation-based education on communication skill and clinical competence in maternity nursing practicum. Korean J Women Health Nurs [Internet]. 2012;18(4):312-320. https://doi.org/10.4069/kjwhn.2012.18.4.312 Accessed on May 30, 2018.

40. Lee J, Lee, Y, Lee S, \& Bae J. Effects of high-fidelity patient simulation led clinical reasoning: Focus on nursing core competencies, problem-solving, and academic self-efficacy. Jpn J Nurs Sci [Internet]. 2016;3(1):20-28. [PMID: 26011663].

41. Ignacio J, Dolmans D, Scherpbier A, et al. Comparison of standardized patients with high-fidelity simulators for managing stress and improving performance in clinical deterioration: A mixed methods study. Nurse Educ Today. 2015;35(2):11611168. [PMID: 26047602].

42. Leonard B, Shuhaibar ELH, Chen RC. Nursing student perceptions of intraprofessional team education using high-fidelity simulation. J Nurs Educ. 2010;90(1):628-631. [PMID: 20669872].

43. Alluri RK, Tsing $P$, Lee $E$, Napolitano J. A randomized controlled trial of high-fidelity simulation versus lecture-based education in preclinical medical students. Med Teach. 2016;38(4):404-409. [PMID 25897707]

44. Nguyen K, Khallouq BB, Schuster A., et al. (2017). Developing a tool for observing group critical thinking in first-year medical students: A pilot study using physiology-based, high-fidelity patient simulations. Adv Physiol Educ. 2017;41(4):604611. [PMID: 29138219].

45. Teske S, Peterson DT, Morse A, et al. Utilizing high-fidelity simulation to teach pediatric residents clinical nutrition. ICAN: Infant, Child, Adolescent Nutrition [Internet]. 2015;7(6):367-374. https://doi.org/10.1177/1941406415616869 Accessed on July 10, 2010.

46. Smith MA, Mohammad RA, Benedict N. (2014). Use of virtual patients in an advanced therapeutics pharmacy course to promote active, patients-centered learning. Am J Pharm Educ. 2014;78(6):Article 125,1-7. [PMID: 25147397].

47. Gibbs DM, Dietrich M, Dagnan E. Using high-fidelity simulation to impact occupational therapy student knowledge, comfort, and confidence in acute care. OJOP [Internet]. 2017:5(1):Article 10. [cited 2018 Jun 7]. https://doi.org/10.15453/21686408.1225 Accessed on May 27, 2018.

48. Silberman NJ, Litwin B, Panzarella KJ, Fernandez-Fernandes A. High-fidelity human simulation improves physical therapist student self-efficacy for acute care clinical practice. J Phys Ther Educ [Internet]. 2016;30(1):14-24.

https://journals.Iww.com/jopte/Abstract/2016/30010/High_Fidelity_Human_Simulation_Improves_Physical.3.aspx Accessed on May 3, 2018.

49. Todd, J. C., McCarroll, C. S., \& Nucci, A. M. High-fidelity simulation increases dietetic students' self-efficacy prior to clinical supervised practice: A preliminary study. J Nutr Educ Behav. 2016;48(8):563-567. [PMID: 27423941].

50. Paige JT, Garbee DD, Kozmenko V, et al. Getting a head start: High-fidelity, simulation-based operating team training of interprofessional students. J Am Coll Surg. 2014:218(1):140-149. [PMID: 24183570].

51. George K. Incorporating interprofessional simulations in dietetics education (master's thesis). University of Kansas; 2014. http://hdl.handle.net/1808/15769 Accessed on April 4, 2018.

52. Luctkar-Flude $\mathrm{M}$, Baker $\mathrm{C}$, Pulling $\mathrm{C}$, et al. Evaluating an undergraduate interprofessional simulated-based educational module: Communication, teamwork, and confidence performing cardiac resuscitation skills. Adv Med Educ Pract [Internet], 2010 [cited 2010 Nov 8];2010;59-66. [PMID: 23745064].

53. Tofil MN, Morris JL, Peterson D, et al. Interprofessional simulation training improves knowledge and teamwork in nursing and medical students during internal medicine clerkship. J Hosp Med. 2014;9(3):189-192. [PMID: 24420579].

54. Simko LC, Rhodes DC, McGinnis KA, Fiedor J. Students' perspectives on interprofessional teamwork before and after an interprofessional pain education course. Am J Pharm Educ. 2017;81(6),Article 104,1-9. [PMID: 28970605].

55. Jakobsen RU, Gran SF, Grimsmo B, et al. Examining participant perceptions of an interprofessional simulation-based trauma team training for medical and nursing students. J Interprof Care. 2018;32(1):80-88. [PMID: 28985089].

56. Titzer JL, Swenty CF, Hoehn WG. An interprofessional simulation promoting collaboration and problem-solving among nursing and allied health professional students. Clin Simul Nurs [Internet]. 2011;8(8):e325-e333. https://doi.org/10.1016/j.ecns.2011.01.001 Accessed on June 12, 2018.

57. Watters C, Reedy G, Ross A, et al. Does interprofessional simulation increase self-efficacy: A comparative study. BMJ Open. 2015;5(1):5472-5479. [PMID: 25586366].

58. Bolesta S, Chmil JV. Interprofessional education among student health professionals using human patient simulation. AJPE. 2014;78(8):Article 94. [PMID: 24954934].

59. Kim TE, Shankel T, Reibling ET, et al. Healthcare students interprofessional critical event/disaster response course. Am J Disaster Med. 2017;12(1):11-26. [PMID: 28822211].

(c) The Internet Journal of Allied Health Sciences and Practice, 2019 
60. Vyas D, McCulloh R, Dyer C, Gregory G, Higbee D. An interprofessional course using human patient simulation to teach patient safety and teamwork skills. Am J Pharm Educ. 2013;76(4):Article 71. [PMID: 22611280].

61. Brashers V, Erickson JM, Owen JA, Thomas SM, Conaway MR. Measuring the impact of clinically relevant interprofessional education on undergraduate medical and nursing student competencies: A longitudinal mixed methods approach. $J$ Interprof Care. 2016;30(4):448-457. [PMID: 27269441].

62. Hayden JK, Smiley RA, Alexander M, Kardong-Edgren S, Feffries PR. The NCSBN National Simulation Study: A longitudinal, randomized, controlled study replacing clinical hours with simulation in prelicensure nursing education. JNR. 2014;5(2):5-62. https://www.journalofnursingregulation.com/article/S2155-8256(15)30062-4/abstract Accessed on May 31, 2018.

63. Kopacek KB, Dopp AL, Dopp JM, Vardeny O, Sims JJ. Pharmacy students' retention of knowledge and skills following training in automated external defibrillator use. Am J Pharm Educ. 2010;74(6):Article 109. [PMID: 21045951].

64. Boet S, Borges BC, Naik VN, Siu LW, Riem N, Chandra D, et al. Complex procedural skills are retained for minimum of one year after a single high-fidelity simulation training session. Br J Anaesth. 2011;107:533-539. [PMID: 21659406].

65. Crea KA. Practice skill development through the use of human patient simulation. Am J Pharm Educ. 2011;75(6):Article 188. [PMID: 22171116].

66. White A, Brannan J, Long J, Kruszka K. Comparison of instructional methods: Cognitive skills and confidence levels. Clin Simul Nurs. 2013;9(10):e417-e423. https://www.sciencedirect.com/science/article/pii/S1876139912003738 Accessed on May 27, 2018.

67. Laschinger S, Medves J, Pulling C, McGraw R, Waytuck B, et al. Effectiveness of simulation on health profession students' knowledge, skills, confidence and satisfaction. Int J Evid Based Healthc. 2008;6(3):278-302. [PIMD: 21631826].

68. Gordon CJ, Buckley T. The effect of high-fidelity simulation training on medical-surgical graduate nurses' perceived ability to respond to patient clinical emergencies. J Contin Educ Nurs. 2009;40(11):491-498. [PMID: 19904861].

69. Groves RM, Fowler FJ, Couper MP, Lepkowski JM, Singer E, Tourangeau R. Survey methodology. 2nd ed. Hoboken, NJ: Wiley and Sons; 2009.

\section{Conflict of Interest}

The author certifies that she has NO affiliations with or involvement in any organization or entity with any financial interest, or nonfinancial interest (such as personal or professional relationships, affiliations, knowledge, or beliefs) in the subject matter or materials discussed in this manuscript. 